\title{
Star-shaped triarylamines - One-step metal-free synthesis and optoelectronic properties
}

\section{Meli, Alessandra}

2019-10

Meli , A, Ebenhoch, B , Kutonova , K, Bihlmeier, A, Feyrer, A, Deck, E, Breher , F , Nieger , M , Colsmann , A \& Bräse , S 2019 , ' Star-shaped triarylamines - One-step metal-free synthesis and optoelectronic properties ' , Synthetic Metals , vol. 256 , 116138 . https://doi.org/10.1016/j.s

http://hdl.handle.net/10138/334796

https://doi.org/10.1016/j.synthmet.2019.116138

cc_by_nc_nd

acceptedVersion

Downloaded from Helda, University of Helsinki institutional repository.

This is an electronic reprint of the original article.

This reprint may differ from the original in pagination and typographic detail.

Please cite the original version. 


\section{Star-shaped triarylamines - one-step metal-free synthesis and optoelectronic properties}

Alessandra Meli, ${ }^{\mathrm{a}, \mathrm{b}}$ Bernd Ebenhoch, ${ }^{\mathrm{b}, \mathrm{c}}$ Ksenia Kutonova, ${ }^{\mathrm{a}, \mathrm{b}}$ Angela Bihlmeier, ${ }^{\mathrm{d}}$ Alexander Feyrer, ${ }^{\mathrm{e}}$ Eva Deck, ${ }^{\mathrm{e}}$ Frank Breher, ${ }^{\mathrm{e}}$ Martin Nieger, ${ }^{\dagger}$ Alexander Colsmann ${ }^{\mathrm{b}, \mathrm{c}}$ and Stefan Bräse ${ }^{a, b, g, *}$

a Institute of Organic Chemistry (IOC), Karlsruhe Institute of Technology (KIT), Fritz-HaberWeg 6, 76131 Karlsruhe, Germany

${ }^{b}$ Material Research Center for Energy Systems (MZE), Karlsruhe Institute of Technology (KIT), Strasse am Forum 7, 76131 Karlsruhe, Germany

c Light Technology Institute (LTI), Karlsruhe Institute of Technology (KIT), Engesserstrasse 13, 76131 Karlsruhe, Germany

d Institute of Physical Chemistry (IPC), Karlsruhe Institute of Technology (KIT), Fritz-HaberWeg 2, 76131 Karlsruhe, Germany

e Institute of Inorganic Chemistry (AOC), Karlsruhe Institute of Technology (KIT), Engesserstrasse 15, 76131 Karlsruhe, Germany

${ }^{f}$ Department of Chemistry, University of Helsinki, P. O. Box 55, 00014 Helsinki, Finland

9 Institute of Toxicology and Genetics (ITG), Karlsruhe Institute of Technology (KIT), Hermannvon-Helmholtz-Platz 1, 76344 Eggenstein-Leopoldshafen, Germany

*Email: stefan.braese@kit.edu

Keywords: base-promoted homolytic aromatic substitution, direct arylation, triarylamines, hole-transport materials 


\begin{abstract}
Triarylamine derivatives are often implemented in organic optoelectronic devices due to their excellent hole-transport properties and their versatile structural tuneability. Common synthetic routes to obtain functionalized triarylamines follow multi-step procedures utilizing transition metal catalysts. Here, we investigate the synthesis of a series of star-shaped tris(biphenylamines) by a one-step base-promoted homolytic aromatic substitution (BHAS), simultaneously attaching three peripheral arenes to the triarylamine core. We demonstrate the versatility of this synthetic route by coupling four different functionalized arenes to the core and study their influence on the optoelectronic properties. BHAS as a metal-free synthetic route produces pure organic semiconductors without transition metal residues.
\end{abstract}

\title{
1. Introduction
}

Organic molecules based on triarylamine (TAA) cores represent recurrent structural motifs in functional organic semiconductors, used, for example, in optoelectronic devices such as organic light-emitting diodes (OLEDs), organic solar cells and organic field-effect transistors (OFETs). ${ }^{1-5}$ The efficient oxidation occurring at the electron-donating nitrogen center and the ability to transport positively charged carriers via radical cations, render triarylamine derivatives excellent semiconductors for the implementation of hole-transport layers (HTLs). ${ }^{6}$ Importantly, their high transparency in the visible spectral regime warrants no parasitic absorption. The properties of TAAs can be tailored by designing structures with extended $\pi$-conjugation, obtained by connecting the aromatic moieties via para-linkages on the peripheral arenes. The results are star-shaped, branched or dendritic structures, which reduce aggregation and provide lower oxidation energies together with higher electroluminescent stability. ${ }^{7-12}$

Most organic semiconductors exhibit less environmental hazards than inorganic semiconductors, which makes organic semiconductors stand out from the semiconductor family and may well be an enabler for a sustainable future semiconductor technology. In light of this sustainability, there is also a growing consensus on rethinking the traditional organic synthesis in order to establish new heavy-metal-free synthetic methods. ${ }^{13-15}$ This is not only important from an environmental point of view but also can enhance the performance and reproducibility of the respective optoelectronic devices, since even lowest metal traces and concurrent metal-organic interactions can influence the electronic properties. ${ }^{16,17}$

So far, TAAs have been synthesized by reacting two pre-functionalized coupling partners in the presence of transition metal catalysts (e.g. Mizoroki-Heck, Negishi, Stille or SuzukiMiyaura cross-couplings). ${ }^{18-21}$ The reported synthetic routes to obtain TAA derivatives endcapped with phenyl ${ }^{12,22-24}$ or fluorinated phenyl groups ${ }^{24-26}$ employed a one-step nickel- or palladium-catalyzed cross-coupling. In this work, we lay out a heavy-metal-free synthesis route 
using the innovative base-promoted homolytic aromatic substitution (BHAS, also referred to as direct arylation), ${ }^{27}$ as illustrated in Scheme 1. BHAS has attracted tremendous attention since its first application in the transition-metal-free biaryl coupling. ${ }^{28}$ The BHAS methodology generates $\mathrm{C}-\mathrm{C}$ bonds between aryl halides (mostly iodides and bromides) and arenes through a radical chain reaction, promoted by an initiation system comprising a base and an activating organic additive. ${ }^{29-32}$ Most reports focused on bases such as tert-butoxides ( $t$-BuOM, $M=K$ or $\mathrm{Na}),{ }^{33-71}$ with $t$-BuOK being the most efficient, ${ }^{28,38-47}$ but also potassium ethoxide (EtOK) ${ }^{48}$ and potassium tert-amylate $(t-A m O K)^{49}$ can mediate the reaction process. A wide variety of activating organic additives is used alongside the base, ranging from diamine ligands $\left(N, N^{\prime}\right.$ dimethylethylenediamine, ${ }^{43,44,49-53}$ 1,10-phenanthroline and its derivatives, ${ }^{43,47-49,53-63}$ hydrazine and its derivatives $\left.{ }^{41,64}\right)$ over alcohols ${ }^{49,51,53,65}$ and 1,2-diols ${ }^{49,51}$ to $N$-heterocycles (pyridines, ${ }^{38,40,57}$ quinolines, ${ }^{46}$ and carbenes ${ }^{66}$ ), porphyrin, ${ }^{67}$ amino acids, ${ }^{45,49,51}$ and metalorganic frameworks. ${ }^{68}$ Furthermore, BHAS has served as a multi-bond forming reaction, realizing the double biaryl coupling of dihalobenzenes with benzene and achieving extended T-electron systems. ${ }^{39-42,48,49,52,54,56,69-71}$ A significant contribution to the development of the multi-bond forming BHAS methodology comes from the work of Masters who performed both intra- and intermolecular BHAS on scaffolds bearing two halogen groups on different arenes in the presence of coupling partners not limited to benzene. ${ }^{56}$

Inspired by those results, we targeted a novel one-step transition-metal-free multi-bond forming synthesis of substituted star-shaped triarylamines. We report on the simultaneous coupling between three reactive iodo-functionalities located on the three aromatic rings of the triarylamine moiety and symmetrical arenes as coupling partners. This synthetic strategy allowed the synthesis of three novel compounds, i.e. tris(2',5'-difluoro-[1,1'-biphenyl]-4yl)amine, tris(2',5'-dimethylbiphenyl-4-yl)amine and tris(2',5'-dimethoxybiphenyl-4-yl)amine as well as the previously reported tri(biphenyl-4-yl)amine. The optoelectronic properties of these compounds were compared.

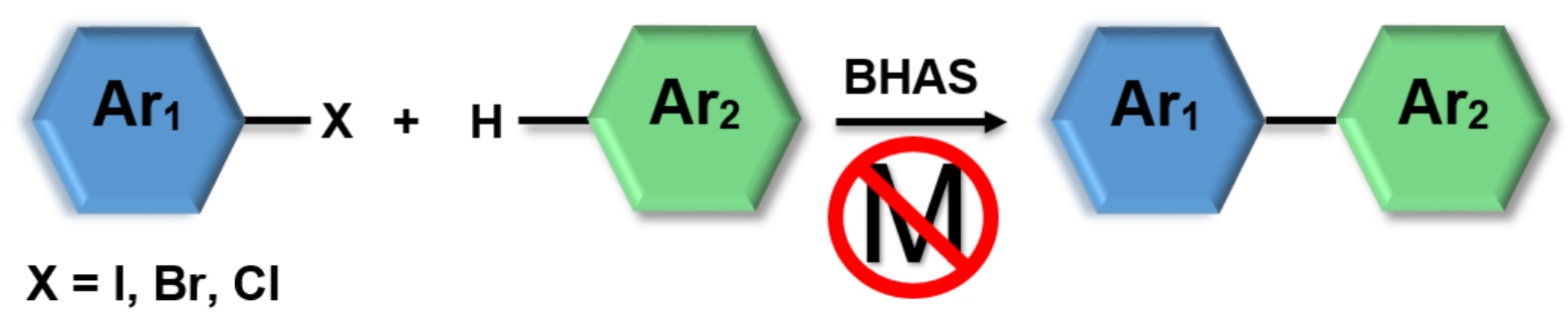

Scheme 1. Base-promoted homolytic aromatic substitution (BHAS) for direct $\mathrm{C}-\mathrm{H}$ activation.

\section{Results and discussion}

\subsection{Synthesis}


Promising earlier reports on the synthesis of fluorinated biaryls via the BHAS methodology, prompted us to apply the established reaction conditions to the synthesis of TAAs. ${ }^{54} \mathrm{We}$ performed the biaryl coupling of tris(4-iodophenyl)amine 1 with benzene $2 a$ at $100{ }^{\circ} \mathrm{C}$ (Table 1, Entry 1) using 1,10-phenanthroline 4 (0.90 equiv.) as activating organic additive in combination with $t$-BuOK (9.0 equiv.) and an excess of the corresponding arene (80-100 equiv.) as coupling partner as well as solvent (Scheme 2). The reaction proceeded over $4 \mathrm{~h}$, delivering the desired product tris(biphenyl-4-yl)amine $3 \mathbf{a}$ in $27 \%$ yield. To study the temperature dependence of the reaction, we conducted the BHAS at elevated temperatures and stopped the reaction once the starting material 1 was completely consumed, as revealed by thin layer chromatography (TLC). At $120^{\circ} \mathrm{C}$ and at $140{ }^{\circ} \mathrm{C}$, the reaction was completed within $3 \mathrm{~h}$ and $1 \mathrm{~h}$, respectively, with no significant changes in the yield (Table 1, Entries 2 and 3). The reaction time further decreased to $30 \mathrm{~min}$ at a temperature of $160{ }^{\circ} \mathrm{C}$ leading to a 30 $\%$ yield of $\mathbf{3 a}$ (Table 1, Entry 4). Repeating the biaryl coupling for a prolonged reaction time (24 h, Entries 5-7) did not lead to any further improvements of the yield, indicating an accelerated biaryl coupling at higher temperatures. Zhou et al. suggested that the initiation of the transition-metal-free $\mathrm{C}-\mathrm{H}$ arylation of arenes with aryl halides is based on the in situ formation of organic electron donors from $t$-BuOK and an additive, and requires thermal activation. ${ }^{51,57}$ Therefore, high temperatures accelerate the reaction initiation. It also provides evidence that the nature of the organic additive plays an important role in the BHAS reaction. ${ }^{54}$ To improve the yield of the target product, we have explored six alternative additives, i.e. $\mathrm{N}$ methylglycine 5, cyclopentanone 6, 3,3-dimethyl-2-butanone 7, N,N'-dimethylethylendiamine 8, (1R,2R)-cyclohexane-1,2-diamine 9 and (1R,2R)-cyclohexane-1,2-diol 10 (Scheme 3; Table 1, Entries 8-13).
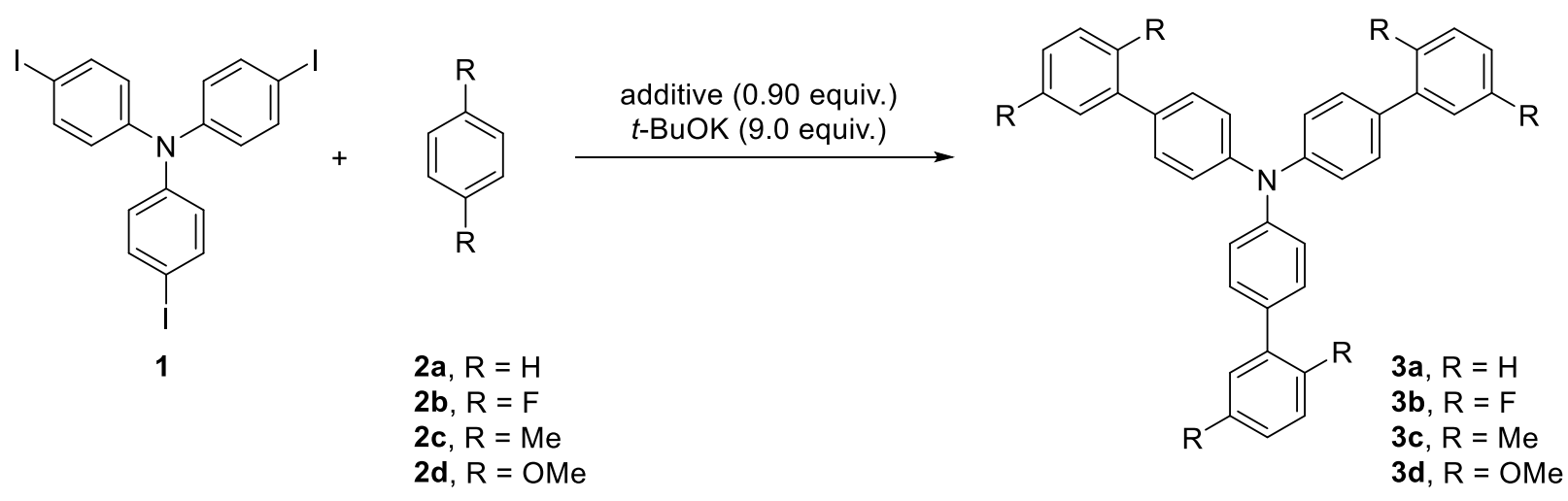

Scheme 2. Synthesis of the TAAs $\mathbf{3 a - 3} \mathbf{d}$ using an organic additive in combination with $t$-BuOK and an excess of the arenes $\mathbf{2 a - 2 d}$. 


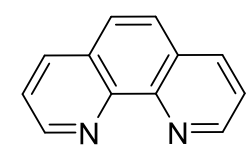

9,10-phenantroline

4<smiles>CNCCNC</smiles>

$N, N^{\prime}$-dimethylathylenediamine<smiles>CNCC(=O)O</smiles>

N-methylglycine

5<smiles>N[C@H]1CCCC[C@H]1N</smiles>

$(1 R, 2 R)$-cyclohexane-1,2-diamine

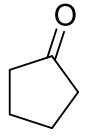

cyclopentanone

6<smiles>CC(=O)C(C)(C)C</smiles>

3,3-dimethyl-2-butanone

7<smiles>O[C@H]1CCCC[C@H]1O</smiles>

(1R,2R)-cyclohexane-1,2-diol

10

Scheme 3. Organic additives 4-10, investigated in the synthesis of TAA $\mathbf{3 a}$ in combination with $t$-BuOK.

Table 1. BHAS of arenes with tris(4-iodophenyl)amine 1.

\begin{tabular}{|c|c|c|c|c|c|}
\hline Entry & Arene & Additive & $\begin{array}{c}\text { Temperature } \\
\left.\mathbf{(}{ }^{\circ} \mathbf{C}\right)\end{array}$ & $\begin{array}{c}\text { Reaction } \\
\text { Time }\end{array}$ & $\begin{array}{c}\text { Yield }^{\mathbf{b}} \\
\mathbf{( \% )}\end{array}$ \\
\hline $\mathbf{1}$ & benzene, 2a & $\mathbf{4}$ & 100 & $4 \mathrm{~h}$ & 27 \\
\hline $\mathbf{2}$ & $\mathbf{2 a}$ & $\mathbf{4}$ & 120 & $3 \mathrm{~h}$ & 27 \\
\hline $\mathbf{3}$ & $\mathbf{2 a}$ & $\mathbf{4}$ & 140 & $1 \mathrm{~h}$ & 30 \\
\hline $\mathbf{4}$ & $\mathbf{2 a}$ & $\mathbf{4}$ & 160 & $30 \mathrm{~min}$ & $30 / 85^{\mathrm{c}}$ \\
\hline $\mathbf{5}$ & $\mathbf{2 a}$ & $\mathbf{4}$ & 100 & $24 \mathrm{~h}$ & 25 \\
\hline $\mathbf{6}$ & $\mathbf{2 a}$ & $\mathbf{4}$ & 120 & $24 \mathrm{~h}$ & 28 \\
\hline $\mathbf{7}$ & $\mathbf{2 a}$ & $\mathbf{4}$ & 140 & $24 \mathrm{~h}$ & 27 \\
\hline $\mathbf{8}$ & $\mathbf{2 a}$ & $\mathbf{5}$ & 160 & $30 \mathrm{~min}$ & $64^{\mathrm{c}}$ \\
\hline $\mathbf{9}$ & $\mathbf{2 a}$ & $\mathbf{6}$ & 160 & $30 \mathrm{~min}$ & $43^{\mathrm{c}}$ \\
\hline $\mathbf{1 0}$ & $\mathbf{2 a}$ & $\mathbf{7}$ & 160 & $30 \mathrm{~min}$ & $36^{\mathrm{c}}$ \\
\hline $\mathbf{1 1}$ & $\mathbf{2 a}$ & $\mathbf{8}$ & 160 & $30 \mathrm{~min}$ & $44^{\mathrm{c}}$ \\
\hline $\mathbf{1 2}$ & $\mathbf{2 a}$ & $\mathbf{9}$ & 160 & $30 \mathrm{~min}$ & $74^{\mathrm{c}}$ \\
\hline $\mathbf{1 3}$ & $\mathbf{2 a}$ & $\mathbf{1 0}$ & 160 & $30 \mathrm{~min}$ & $73^{\mathrm{c}}$ \\
\hline $\mathbf{1 4}$ & 1,4-difluorobenzene, 2b & $\mathbf{4}$ & 160 & $30 \mathrm{~min}$ & 29 \\
\hline $\mathbf{1 5}$ & 1,4-dimethylbenzene, 2c & $\mathbf{4}$ & 160 & $30 \mathrm{~min}$ & 6 \\
\hline $\mathbf{1 6}$ & 1,4-dimethoxybenzene, 2d & $\mathbf{4}$ & 160 & $30 \mathrm{~min}$ & 16 \\
\hline
\end{tabular}

${ }^{2}$ The reaction was carried out in argon atmosphere using tris(4-iodophenyl)amine (1: $\left.0.160 \mathrm{mmol}\right)$, organic additives 4-10 (0.144 mmol), $t$-BuOK (1.44 mmol) and arenes $\mathbf{2 a - 2 d}(2 \mathrm{~mL})$ in a sealed vial. ${ }^{b}$ Isolated yields. ${ }^{c}$ Yields were determined using HPLC and the internal standard (9,10-dimethylanthracene).

We found that, under the applied conditions, 9,10-phenantroline remains the additive of choice to produce the desired tris(biphenyl-4-yl)amine $3 a$ in $85 \%$ yield (Table 1, Entry 4), as determined using HPLC with internal standard (9,10-dimethylanthracene). The amino acid Nmethylglycine 5 (Table 1, Entry 8), the ketones 6 and 7 (Table 1, Entries 9, 10), as well as N,N'-dimethylethylendiamine 8 (Table 1, entry 11) showed moderate activity, while the cyclic compounds (1R,2R)-cyclohexane-1,2-diamine 9 and (1R,2R)-cyclohexane-1,2-diol 10 (Table 
1, Entries 12, 13) demonstrated similar activity and enabled the product formation in high yield. We conclude that the moderate isolated yields of the product stem from losses during purification due to the product's poor solubility and high hydrophobicity. We note that the isolated yields of symmetric star-shaped TAA derivatives are often in the range of $30-50 \%$, even when conventional Pd-catalyzed reactions are performed. ${ }^{72-77}$ Thus, the transition-metalfree synthesis route is a good alternative to the existing synthetic methods using metal catalysts.

The optimized conditions have been used to extend the concept for reactions with other arenes - 1,4-difluorobenzene $\mathbf{2 b}$, 1,4-dimethylbenzene $\mathbf{2 c}$ and 1,4-dimethoxybenzene $\mathbf{2 d}$ leading to $\operatorname{tris}\left(2^{\prime}, 5^{\prime}\right.$-difluoro-[1,1'-biphenyl]-4-yl)amine $3 \mathbf{b}$, tris(2',5'-dimethyl-[1,1'-biphenyl]-4-yl)amine 3c and tris $\left(2\right.$ ', $5^{\prime}$-dimethoxy-[1,1'-biphenyl]-4-yl)amine $3 \mathbf{d}$, respectively. In all cases symmetrical arenes served as coupling partners and as solvents, with an arene to tris(4-iodophenyl)amine $\mathbf{1}$ excess of $80-100$ equiv. While the reactions with $\mathbf{2 a}$ and $\mathbf{2 b}$ proceeded with satisfactory yields of $26-30 \%$, the isolated yields of $\mathbf{3 c}$ and $\mathbf{3 d}$ are drastically lower (6\% and $16 \%$ respectively, Table 1, Entries 15 and 16). In both cases, a wide range of byproducts were obtained, making the isolation procedure significantly more complicated and leading to great losses during purification.

\subsection{Density functional theory calculations}

To gain insight into the electronic and optical properties of the synthesized compounds $\mathbf{3 a}-\mathbf{3 d}$, we performed quantum chemical calculations using density functional theory (DFT) and timedependent density functional theory (TDDFT) methods as implemented in TURBOMOLE (see Supporting Information for more details). ${ }^{72}$ Solvent effects were included via the continuum solvent model COSMO. ${ }^{73}$ The molecular conformation was chosen based on the single crystal X-ray structure of compound $\mathbf{3 b}$ (see Supporting Information) and optimized by DFT at the B3LYP/def2-TZVP level of theory. ${ }^{74,75}$ We observed that the phenyl-phenyl torsion angle depends on the spatial requirements of the substituents. The average phenyl-phenyl torsion angle $\varphi$ amounts to $37.3^{\circ}$ for compound $3 \mathbf{a}$ (exp. $\left.35.4^{\circ}\right),{ }^{17} 40.8^{\circ}$ for compound $\mathbf{3 b}$ (exp. $40.2^{\circ}$ ), and further increases for compounds $3 \mathbf{c}\left(54.9^{\circ}\right)$ and $\mathbf{3 d}\left(46.0^{\circ}\right)$.

The absorption properties in tetrahydrofuran (THF) solution were computed by TDDFT at the B3LYP/def2-SVPD level of theory. ${ }^{82}$ We obtain vertical absorptions with wavelengths in the range between $376 \mathrm{~nm}$ (3b) and $350 \mathrm{~nm}$ (3c), see Table 2. They correspond to transitions from the highest occupied molecular orbital (HOMO, located at the nitrogen atom and the neighbouring three phenyl rings) to the nearly degenerate lowest unoccupied molecular orbitals (LUMO and LUMO+1, located at the three biphenyl moieties). The observed shift of the absorption wavelengths of compounds $\mathbf{3} \mathbf{b}-\mathbf{3} \mathbf{d}$ compared to compound $\mathbf{3} \mathbf{a}$ is related to both the phenyl-phenyl torsion angle (the overlap of the m-electron systems is proportional to cos 
$\varphi)$ and the electronic nature of the substituents (ability to increase the $\pi$-electron system as well as electron donating/withdrawing effects).

In order to estimate the ionization energy by DFT in $\mathrm{CH}_{2} \mathrm{Cl}_{2}$ solution, we used both the HOMO energy ( $\left(-\varepsilon_{\text {номо }}\right)$ as well as the energy difference between the neutral and the cationic species (vertical ionization energy, VIE). Both approaches delivered almost identical data for each of the investigated compounds (Table 2). The smallest ionization energy was found for compound $\mathbf{3 d}$ and the largest one for compound $\mathbf{3 b}$.

Table 2. Average phenyl-phenyl torsion angles $(\varphi)$, vertical absorptions $(\lambda)$, HOMO energies $\left(\varepsilon_{\text {HOMO }}\right)$ and vertical ionization energies (VIE) of compounds $\mathbf{3 a}-\mathbf{3 d}$, obtained from density functional theory (DFT) and time-dependent density functional theory (TDDFT) calculations including solvent effects (THF for $\lambda, \mathrm{CH}_{2} \mathrm{Cl}_{2}$ for $\varepsilon \mathrm{HOMO}$ and VIE).

\begin{tabular}{ccccc}
\hline Compound & $\varphi\left(^{\circ}\right)$ & $\lambda(\mathrm{nm})$ & $-\varepsilon_{\text {HOMO }}(\mathrm{eV})$ & VIE $(\mathrm{eV})$ \\
\hline 3a & 37.3 & 369 & 5.11 & 5.12 \\
3b & 40.8 & 376 & 5.28 & 5.29 \\
3c & 54.9 & 350 & 5.09 & 5.12 \\
3d & 46.0 & 367 & 4.99 & 5.00 \\
\hline
\end{tabular}

\subsection{Optoelectronic characterization of compounds $3 a-3 d$}

Absorption: The absorbance spectra of the compounds are in good agreement with the TDDFT calculation above. The spin-coated films of compounds $\mathbf{3 a - 3 d}$, as depicted in Figure 1, show a strong optical transition in the UV-region and indicate energy gaps of the semiconductors of more than $3 \mathrm{eV}$. In the visible spectral regime, the absorption is negligible as it is commonly observed for TAAs and their derivatives that are used in organic semiconductor devices. The experimentally measured absorption peaks (Table 3 ) are only slightly but systematically blueshifted by approximately $20 \mathrm{~nm}$ versus the TDDFT calculations (Table 2). Due to the small energetic difference between the HOMO $\rightarrow$ LUMO and the HOMO $\rightarrow$ LUMO+1 transitions, their corresponding absorption peaks overlap and appear as one single peak. 


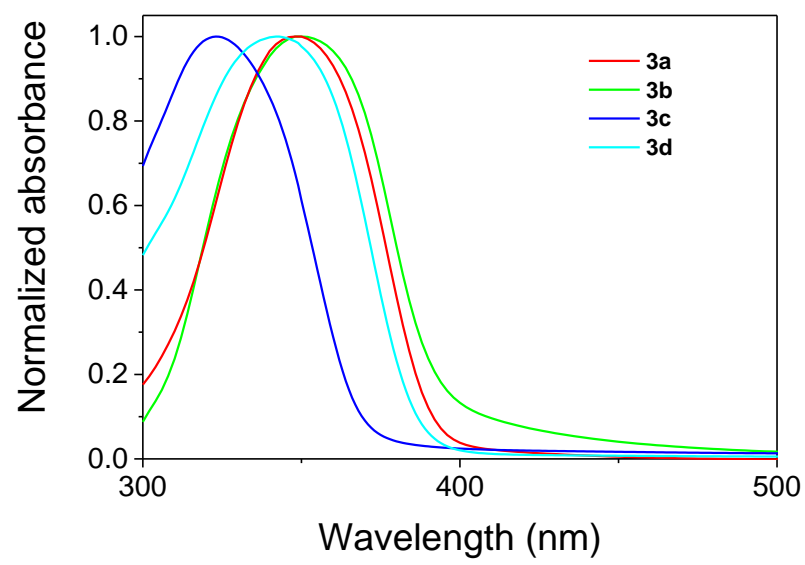

Figure 1. Normalized absorbance spectra of TAA thin-films spin-coated from THF solution. All compounds exhibit only one single absorption peak which includes the thermally broadened HOMO $\rightarrow$ LUMO and the HOMO $\rightarrow$ LUMO+1 transitions.

Electrochemistry: In order to experimentally verify the ionization energies that were predicted by DFT calculations on the synthesized compounds, we performed cyclic voltammetry (CV) in solution. The measurements were performed under argon atmosphere in dry $\mathrm{CH}_{2} \mathrm{Cl}_{2}$ with 0.1 $\mathrm{M}$ tetrabutylammonium hexafluorophosphate as electrolyte, using a platinum disc working electrode, a platinum counter electrode and a silver (pseudo)reference electrode (see also Supporting Information). All energies are referenced against the ferrocene/ferrocenium couple ( $\mathrm{Fc} / \mathrm{Fc}^{+}$, internal standard). As depicted in Figure 2, all compounds are electroactive and show several (quasi)reversible and irreversible redox events. Two (quasi)reversible oxidation waves with half-wave energies of $E_{1 / 2}^{0}(\mathbf{3 a})=0.43 \mathrm{~V}$ and $E_{1 / 2}^{0}(\mathbf{3} \mathbf{b})=0.59 \mathrm{~V}$ are visible. The compounds $\mathbf{3 c}$ and $\mathbf{3 d}$, however, exhibit no reversible oxidation. The origin of the redox processes at energies $>0.7 \mathrm{~V}$ remains unclear. The electron-withdrawing nature of the fluorine substituents in $\mathbf{3 b}$ produces an anodic shift of the oxidation energy of $\mathbf{3} \mathbf{b}$ versus $\mathbf{3} \mathbf{a}$. Referencing to the commonly accepted ionization energy $\mathrm{IE}=4.80 \mathrm{eV}$ of ferrocene ${ }^{78}$, we obtained ionization energies of $5.23 \mathrm{eV}$ for $\mathbf{3 a}$ and $5.39 \mathrm{eV}$ for $\mathbf{3 b}$ (Table 3 ) which is in good agreement with the VIEs from DFT calculations. The (quasi)reversibility of both oxidation events with peak energy differences of $\Delta E_{\mathrm{p}}=\left|E_{\mathrm{pa}}-E_{\mathrm{pc}}\right|=87 \mathrm{mV}$ (3a) and $86 \mathrm{mV}(\mathbf{3 b})$ validates the electrochemical stability of the oxidized species, which is important for the operational stability of devices. ${ }^{79}$ 


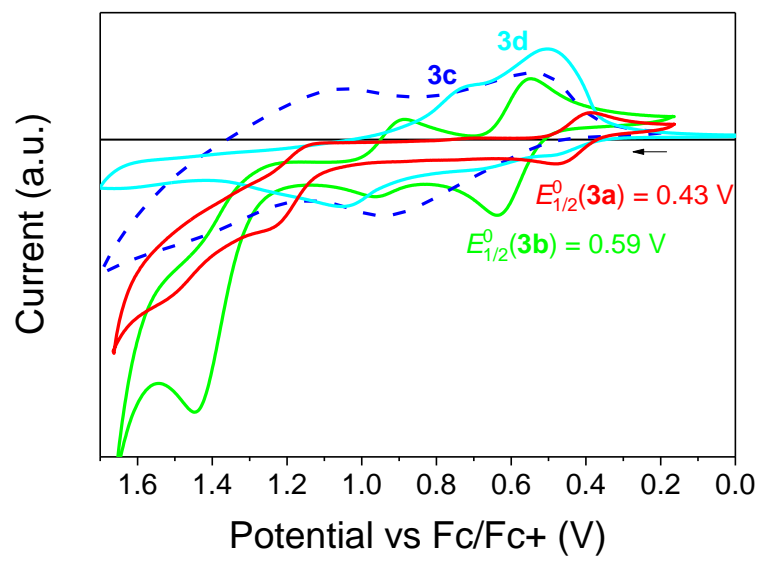

Figure 2. Cyclic voltammogram of $\mathbf{3 a}-\mathbf{3 d}$ in $\mathrm{CH}_{2} \mathrm{Cl}_{2}$ solutions $v s \mathrm{Fc} / \mathrm{Fc}^{+}$(Scan rate: $v=250 \mathrm{mV} / \mathrm{s}$, $\mathrm{Pt} /\left[{ }^{n} \mathrm{Bu}_{4} \mathrm{~N}\right]\left[\mathrm{PF}_{6}\right] / \mathrm{Ag}$ ). The compounds $\mathbf{3 a}$ and $\mathbf{3 b}$ show reversible oxidation at $0.43 \mathrm{eV}$ and $0.59 \mathrm{eV}$, respectively, whereas the oxidation energies of compounds $\mathbf{3} \mathbf{c}$ and $\mathbf{3 d}$ cannot clearly be identified.

Photoelectron Spectroscopy: Whereas CV is ideally suited to compare the electronic properties of molecules isolated in a weak solvent matrix, the design of optoelectronic applications rather requires bulk properties. In the solid state, the transport energies of molecular assemblies can be different than in solution, since molecular interactions can affect the electronic states of the molecules. ${ }^{80}$ Therefore, we determined the ionization energies of thin-films of $\mathbf{3} \mathbf{a}-\mathbf{3} \mathbf{d}$ by photoelectron spectroscopy in air (PESA) from the square root of the photoelectron yield as a function of photon energy, as depicted in Figure 3. The ionization energies $5.60 \mathrm{eV}$ (3a), $5.72 \mathrm{eV}$ (3b), $5.76 \mathrm{eV}$ (3c) and $5.68 \mathrm{eV}$ (3d) (Table 4), are about 0.35 $\mathrm{eV}$ higher than the energies obtained by CV (3a and $\mathbf{3 b}$ ). Notably, the high ionization energies of the TAA derivatives investigated herein are ideally suited towards implementation of the TAA derivatives into organic optoelectronic devices, for example as hole-injection layers in wide-gap or blue-emitting organic light-emitting diodes. By the functional groups investigated here, the ionizations energies could be fine-tuned by $0.16 \mathrm{eV}$, which allows adaptation to the specific requirements of devices. 


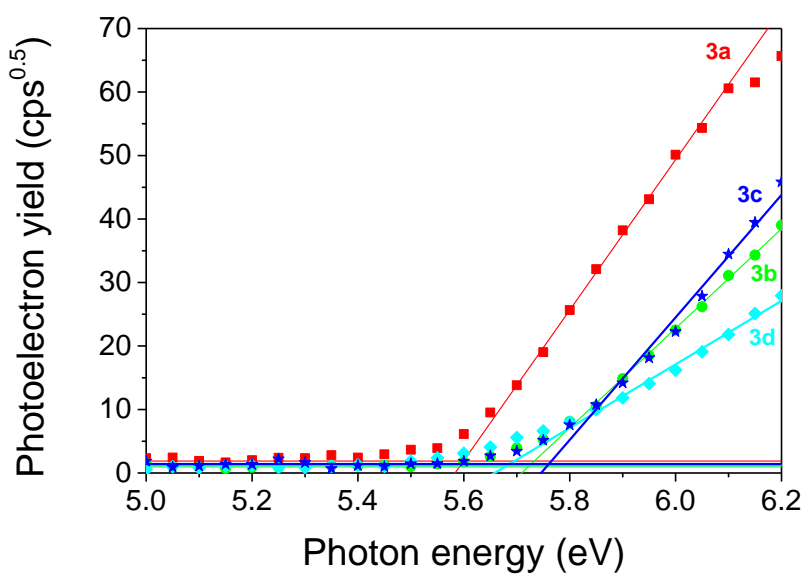

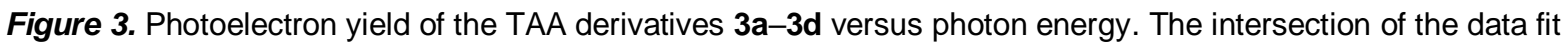
with the baseline marks the ionization energy.

Table 3. Peak absorptions $\left(\lambda_{\max }\right)$ from absorbance spectra of thin-films and ionization energies (IE) estimated by cyclic voltammetry (CV) (vs. IE=4.80 eV of ferrocene) and photoelectron spectroscopy in air (PESA) of compounds 3a-3d.

\begin{tabular}{cccc}
\hline Compound & $\lambda_{\max }(\mathrm{nm})$ & $\mathrm{IE}_{\mathrm{CV}}(\mathrm{eV})$ & $\mathrm{IE}_{\mathrm{PESA}}(\mathrm{eV})$ \\
\hline 3a & 351 & 5.23 & 5.60 \\
3b & 349 & 5.39 & 5.72 \\
3c & 322 & - & 5.76 \\
3d & 342 & - & 5.68 \\
\hline
\end{tabular}

\section{Conclusion}

Triarylamines (TAAs) are important and recurring basic building blocks for complex organic semiconductors. We have demonstrated the principal metal-free, one-step synthesis of TAAs by addition of benzene to tris(4-iodophenyl)amine using BHAS. The synthetic route is versatile in that other substituted arenes can be coupled to the TAA core, such as the commercially available 1,4-difluorobenzene, 1,4-dimethylbenzene, 1,4-dimethoxybenzene, here yielding the novel compounds tris(2',5'-difluoro-[1,1'-biphenyl]-4-yl)amine, tris(2',5'-dimethylbiphenyl-4yl)amine and tris $\left(2^{\prime}, 5^{\prime}\right.$-dimethoxybiphenyl-4-yl)amine. The absorption and electronic properties of the synthesized TAAs were confirmed by DFT and TDDFT calculations and match well the requirements of semiconductors for optoelectronic applications. We have demonstrated, that the optoelectronic properties can be fine-tuned by variation of the substituents on the peripheral arenes. Using other substituents in the future will eventually enable the synthesis of more specialized TAA derivatives with tailored semiconductor properties and high purity. The synthetic procedure presented herein is a good blueprint for a 
heavy-metal-free organic semiconductor synthesis, yielding excellent quality materials. It adds to the toolbox of synthetic procedures towards an all-sustainable organic electronic technology.

\section{Acknowledgements}

This research project was funded by the German Research Council (DFG) within the SFB 1176 (projects C2 and Q4). A.M. and K.K. acknowledge the Ministry of Science, Research and Art Baden-Württemberg (AZ: 33-753-30-20 / 3/3). Electronic Supplementary Information (ESI) available: Experimental procedures, analytical data, crystallographic data for $\mathbf{3 b}$ and details of the computational studies. For ESI and cif-file (3b) see DOI: 10.1039/x0xx00000x. CCDC 1522369 (3b) contains the supplementary crystallographic data for this paper. These data can be obtained free of charge from The Cambridge Crystallographic Data Centre via www.ccdc.cam.ac.uk/data request/cif.

\section{References}

[1] Luponosov, Y. N.; Solodukhin, A. N.; Ponomarenko, S. A. Polym. Sci., Ser. C 2014, 56, 104.

[2] Kwon, J.; Kim, M. K.; Hong, J.-P.; Lee, W.; Lee, S.; Hong, J.-I. Bull. Korean Chem. Soc. 2013, 34, 1355.

[3] Zhao, Z.; Li, Z.; Lam, J. W. Y.; Maldonado, J.-L.; Ramos-Ortiz, G.; Liu, Y.; Yuan, W.; Xu, J.; Miao, Q.; Tang, B. Z. Chem. Commun. 2011, 47, 6924.

[4] Ning, Z.; Tian, H. Chem. Commun. 2009, 5483.

[5] Shirota, Y.; Kageyama, H. Chem. Rev. 2007, 107, 953.

[6] Thelakkat, M. Macromol. Mater. Eng. 2002, 287, 442.

[7] Kuwabara, Y.; Ogawa, H.; Inada, H.; Noma, N.; Shirota, Y. Adv. Mater. 1994, 6, 677.

[8] Tanaka, H.; Tokito, S.; Taga, Y.; Okada, A. Chem. Commun. 1996, 2175.

[9] Kim, B. M.; Nguyen, Q. P. B.; Fan, J. G.; Kim, M. J.; Braveenth, R.; Kim, G. W.; Kwon, J. H.; Chai, K. Y. Bull. Korean Chem. Soc. 2015, 36, 1303.

[10] Jiang, Z.; Ye, T.; Yang, C.; Yang, D.; Zhu, M.; Zhong, C.; Qin, J.; Ma, D. Chem. Mater. 2011, 23, 771.

[11] Justin Thomas, K. R.; Lin, J. T.; Tao, Y.-T.; Ko, C.-W. Chem. Mater. 2002, 14, 1354.

[12] Vamvounis, G.; Shaw, P. E.; Burn, P. L. J. Mater.Chem. C 2013, 1, 1322.

[13] Arunprasath, D.; Sekar, G. Adv. Synth. Catal. 2017, 359, 698.

[14] An, P.; Huo, Y.; Chen, Z.; Song, C.; Ma, Y. Org. Biomol. Chem. 2017, 15, 3203.

[15] Maezono, S. M. B.; Poudel, T. N.; Lee, Y. R. Org. Biomol. Chem. 2017, 15, 2052.

[16] Hung, L. S.; Chen, C. H. Mater. Sci. Eng. R. 2002, 39, 143.

[17] Qin, A.; Lam, J. W. Y.; Dong, H.; Lu, W.; Jim, C. K. W.; Dong, Y.; Häussler, M.; Sung, H. H. Y.; Williams, I. D.; Wong, G. K. L.; Tang, B. Z. Macromolecules 2007, 40, 4879.

[18] Johansson Seechurn, C. C. C.; Kitching, M. O.; Colacot, T. J.; Snieckus, V. Angew. Chem. Int. Ed. 2012, 51, 5062.

[19] Yamamoto, Y. In Copper-Mediated Cross-Coupling Reactions; Evano, G., Blanchard, N., Eds.; John Wiley \& Sons, Inc.: 2013.

[20] You, S.-L.; Xia, J.-B. In C-H Activation; Yu, J.-Q., Shi, Z., Eds.; Springer-Verlag Berlin Heidelberg:, 2010.

[21] McGlacken, G. P.; Bateman, L. M. Chem. Soc. Rev. 2009, 38, 2447.

[22] Inada, H.; Ohnishi, K.; Nomura, S.; Higuchi, A.; Nakano, H.; Shirota, Y. J. Mat. Chem. 1994, 4, 171. 
[23] Higuchi, A.; Ohnishi, K.; Nomura, S.; Inada, H.; Shirota, Y. J. Mat. Chem. 1992, 2, 1109.

[24] Hu, B.; Chen, X.; Wang, Y.; Lu, P.; Wang, Y. Chem. Asian J. 2013, 8, 1144.

[25] Li, Z.; Wu, Z.; Fu, W.; Liu, P.; Jiao, B.; Wang, D.; Zhou, G.; Hou, X. J. Phys. Chem. C 2012, 116, 20504

[26] Li, Z.; Wu, Z.; Jiao, B.; Liu, P.; Wang, D.; Hou, X. Chem. Phys. Lett. 2012, 527, 36.

[27] Studer, A.; Curran, D. P. Angew. Chem. Int. Ed. 2011, 50, 5018.

[28] Yanagisawa, S.; Ueda, K.; Taniguchi, T.; Itami, K. Org. Lett. 2008, 10, 4673.

[29] Chan, T. L.; Wu, Y.; Choy, P. Y.; Kwong, F. Y. Chem. Eur. J. 2013, $19,15802$.

[30] Mehta, V. P.; Punji, B. RSC Adv. 2013, 3, 11957.

[31] Studer, A.; Curran, D. P. Nat. Chem. 2014, 6, 765.

[32] Studer, A.; Curran, D. P. Angew. Chem. Int. Ed. 2016, 55, 58.

[33] Bhakuni, B. S.; Yadav, A.; Kumar, S.; Kumar, S. New J. Chem. 2014, 38, 827.

[34] Wu, Y.; Choy, P. Y.; Kwong, F. Y. Asian J. Org. Chem. 2014, 3, 1262.

[35] Zhu, Y.-W.; Yi, W.-B.; Qian, J.-L.; Cai, C. ChemCatChem 2014, 6, 733.

[36] Yong, G.-P.; She, W.-L.; Zhang, Y.-M.; Li, Y.-Z. Chem. Commun. 2011, 47, 11766.

[37] Yanagisawa, S.; Itami, K. ChemCatChem 2011, 3, 827.

[38] Wu, Y.; Choy, P. Y.; Kwong, F. Y. Org. Biomol. Chem. 2014, 12, 6820.

[39] Cuthbertson, J.; Gray, V. J.; Wilden, J. D. Chem. Commun. 2014, 50, 2575.

[40] A, S.; Liu, X.; Li, H.; He, C.; Mu, Y. Asian J. Org. Chem. 2013, 2, 857.

[41] Dewanji, A.; Murarka, S.; Curran, D. P.; Studer, A. Org. Lett. 2013, 15, 6102.

[42] Sharma, S.; Kumar, M.; Kumar, V.; Kumar, N. Tetrahedron Lett. 2013, 54, 4868.

[43] De, S.; Mishra, S.; Kakde, B. N.; Dey, D.; Bisai, A. J. Org. Chem. 2013, 78, 7823.

[44] De, S.; Ghosh, S.; Bhunia, S.; Sheikh, J. A.; Bisai, A. Org. Lett. 2012, 14, 4466.

[45] Tanimoro, K.; Ueno, M.; Takeda, K.; Kirihata, M.; Tanimori, S. J. Org. Chem. 2012, 77,

[46] Qiu, Y.; Liu, Y.; Yang, K.; Hong, W.; Li, Z.; Wang, Z.; Yao, Z.; Jiang, S. Org. Lett. 2011, 13, 3556.

[47] Shirakawa, E.; Itoh, K.-i.; Higashino, T.; Hayashi, T. J. Am. Chem. Soc. 2010, 132, 15537.

[48] Liu, W.; Liu, R.; Bi, Y. Tetrahedron 2015, 71, 2622.

[49] Liu, W.; Xu, L. Tetrahedron 2015, 71, 4974.

[50] Zhang, L.; Yang, H.; Jiao, L. J. Am. Chem. Soc. 2016, 138, 7151.

[51] Zhou, S.; Doni, E.; Anderson, G. M.; Kane, R. G.; MacDougall, S. W.; Ironmonger, V. M.; Tuttle, T.; Murphy, J. A. J. Am. Chem. Soc. 2014, 136, 17818.

[52] Liu, W.; Cao, H.; Zhang, H.; Zhang, H.; Chung, K. H.; He, C.; Wang, H.; Kwong, F. Y.; Lei, A. J. Am. Chem. Soc. 2010, 132, 16737.

[53] Wu, Y.; Wong, S. M.; Mao, F.; Chan, T. L.; Kwong, F. Y. Org. Lett. 2012, 14, 5306.

[54] Lindner, S.; Bräse, S.; Masters, K.-S. J. Fluorine Chem. 2015, 179, 102.

[55] Xu, Z.; Gao, L.; Wang, L.; Gong, M.; Wang, W.; Yuan, R. ACS Catal. 2015, 5, 45.

[56] Masters, K.-S. RSC Adv. 2015, 5, 29975.

[57] Zhou, S.; Anderson, G. M.; Mondal, B.; Doni, E.; Ironmonger, V.; Kranz, M.; Tuttle, T.; Murphy, J. A. Chem. Sci. 2014, 5, 476.

[58] Li, B.; Qin, X.; You, J.; Cong, X.; Lan, J. Org. Biomol. Chem. 2013, 11, 1290.

[59] Masters, K.-S.; Bräse, S. Angew. Chem. Int. Ed. 2013, 52, 866.

[60] Bhakuni, B. S.; Kumar, A.; Balkrishna, S. J.; Sheikh, J. A.; Konar, S.; Kumar, S. Org. Lett. 2012, 14, 2838.

[61] Sun, C.-L.; Gu, Y.-F.; Huang, W.-P.; Shi, Z.-J. Chem. Commun. 2011, 47, 9813.

[62] Roman, D. S.; Takahashi, Y.; Charette, A. B. Org. Lett. 2011, 13, 3242.

[63] Sun, C.-L.; Li, H.; Yu, D.-G.; Yu, M.; Zhou, X.; Lu, X.-Y.; Huang, K.; Zheng, S.-F.; Li, B.-J.; Shi, Z.-J. Nat. Chem. 2010, 2, 1044.

[64] Song, Q.; Zhang, D.; Zhu, Q.; Xu, Y. Org. Lett. 2014, 16, 5272.

[65] Liu, W.; Tian, F.; Wang, X.; Yu, H.; Bi, Y. Chem. Commun. 2013, 49, 2983.

[66] Chen, W.-C.; Hsu, Y.-C.; Shih, W.-C.; Lee, C.-Y.; Chuang, W.-H.; Tsai, Y.-F.; Chen, P. P.-Y.; Ong, T.-G. Chem. Commun. 2012, 48, 6702.

[67] Ng, Y. S.; Chan, C. S.; Chan, K. S. Tetrahedron Lett. 2012, 53, 3911.

[68] Liu, H.; Yin, B.; Gao, Z.; Li, Y.; Jiang, H. Chem. Commun. 2012, 48, 2033. 
[69] Ghosh, D.; Lee, J.-Y.; Liu, C.-Y.; Chiang, Y.-H.; Lee, H. M. Adv. Synth. Catal. 2014, $356,406$.

[70] Budén, M. E.; Guastavino, J. F.; Rossi, R. A. Org. Lett. 2013, 15, 1174.

[71] Zhao, H.; Shen, J.; Guo, J.; Ye, R.; Zeng, H. Chem. Commun. 2013, 49, 2323.

[72] TURBOMOLE, Program Package for ab initio Electronic Structure Calculations, Version 6.6 [2014], a development of University of Karlsruhe and Forschungszentrum Karlsruhe GmbH, 1989-2007, TURBOMOLE GmbH since 2007, see http://www.turbomole.com.

[73] Klamt, A.; Schuurmann, G. J. Chem. Soc., Perkin Trans. 2 1993, 799.

[74] Becke, A. D. J. Chem. Phys. 1993, 98, 5648.

[75] Weigend, F.; Ahlrichs, R. PCCP 2005, 7, 3297.

[76] Rappoport, D.; Furche, F. J Chem Phys 2010, 133, 134105.

[77] Mallow, O.; Khanfar, M. A.; Malischewski, M.; Finke, P.; Hesse, M.; Lork, E.; Augenstein, T.; Breher, F.; Harmer, J. R.; Vasilieva, N. V.; Zibarev, A.; Bogomyakov, A. S.; Seppelt, K.; Beckmann, J. Chem. Sci. 2015, 6, 497.

[78] Pommerehne, J.; Vestweber, H.; Guss, W.; Mahrt, R. F.; Bässler, H.; Porsch, M.; Daub, J. Adv. Mater. 1995, 7, 551.

[79] Holliday, S.; Ashraf, R. S.; Nielsen, C. B.; Kirkus, M.; Röhr, J. A.; Tan, C.-H.; ColladoFregoso, E.; Knall, A.-C.; Durrant, J. R.; Nelson, J.; McCulloch, I. J. Am. Chem. Soc. 2015, 137, 898.

[80] D’Andrade, B. W.; Datta, S.; Forrest, S. R.; Djurovich, P.; Polikarpov, E.; Thompson, M. E. Org. Electron. 2005, 6, 11. 